\title{
The subsequent impacts of independent and combined drought and heat stress around flowering on maize grain filling: Field and laboratory investigation
}

\author{
Xiwei Liu ${ }^{1}$, Guanying $\mathrm{Chen}^{1}$, Shoubing Huang ${ }^{1}$, Chenchen $\mathrm{Xu}^{1}$, Yonghong $\mathrm{Yu}^{1}$, Xingya \\ Wang $^{1}$, Jia Gao ${ }^{1}$, qingfeng Meng ${ }^{1}$, and $\mathrm{Pu} \mathrm{Wang}^{2}$ \\ ${ }^{1}$ China Agricultural University College of Agronomy and Biotechnology \\ ${ }^{2}$ Affiliation not available
}

May 18, 2020

\begin{abstract}
ABSTRACT Drought along with high temperature around flowering is becoming more frequent to strongly influence maize production. However, the impacts of independent and combined drought and heat stress during this stage on subsequent grain filling have received limited attention. Here we investigated the response of grain development to three stresses (drought, heat and combined drought and heat stresses (DS, HS, DHS)) around flowering in ponds covered with a rain shelter in field. In additional, some grains were incubated in laboratory after pollination. Compared with control treatment, the decreased rate of grain weight was in the order of HS[?]DS[?]DHS in both experiments. In field, grain weight was decreased by 5-11\% in stresses. The leaf senescence was accelerated together with decreased photosynthesis rate. Grain weight was still reduced largely in stresses with sufficient source supply in laboratory, which implicated a subsequent sink (grain) limit by early stresses. This mainly resulted from the disturbed carbohydrate metabolism and starch synthesis such as the activities of surcose invertase, sucrose synthase, ADP Glc pyrophosphorylase and starch synthase at early grain filling stage. This study provided information on how to promote drought and heat tolerance hybrids and mitigated management strategy.
\end{abstract}

\section{1 | INTRODUCTION}

As the first cereal crop in the world, maize production is important to ensure food security (FAO, 2020). Because of the increasing population and feed demand due to diet shift in many areas, the continuous improvement of maize yield is a great challenge in the new era. Maize is sensitive to abiotic stresses such as drought and heat, which are major environmental factors that limit crop growth and productivity (Bonfante et al., 2015; Lizaso et al., 2018; Rossini, Maddonni, \& Otegui 2016; Shen et al., 2018; Waha, Müller, \& Rolinski, 2013). Drought and heat stress has been becoming more sever in time and over space around the world since 1980 (Dai, Trenberth, \& Qian, 2004; Sheffield, Wood, \& Roderick, 2012; Wang, Marija, Dong, Susanne, \& Bernd, 2014; Harrison, Tardieu, Dong, Messina, \& Hammer, 2014). Heat stress is frequently associated with reduced availability of water (Lesk, Rowhani, \& Ramankutty, 2016; Wang et al., 2018), and the occurrence of drought accompanied by heat stress is predicted to increase in future (IPCC, 2014). Therefore, the understanding of independent and combined drought and heat stress impacts on maize during the whole growth duration and the underlying mechanism is pivotal to promote breeding and targeted management measures.

Across the global maize production area, the combined drought and heat stress mostly occurred around flowering (Lesk, Rowhani, \& Ramankutty, 2016; Wang et al., 2018). During this stage, the adverse impacts of the stresses on the male and female maize organs for the seed-set and seed formation have been frequently reported (Bassetti and Westgate, 1993; Edreira, Carpici, Sammarro, \& Otegui, 2011; Marceau, Saint-Jean, 
Loubet, Foueillassar, \& Huber, 2012; Sánchez, Rasmussen, \& Porter, 2014; Wang et al., 2018). The previous studies indicated that maize kernel number was significantly reduced in the stresses because of low pollen number and pollen viability, slow silk-growth and ovary-growth rate, and weak silk receptivity (Alam et al., 2017; Dresselhaus, \& Franklin-Tong, 2013; Wilhelm, Mullen, Keeling, \& Singletary, 1999; Oury, Tardieu, \& Turc, 2016; Oury et al., 2016). For example, the drought stress from tassel emergence to 6 days after silking decreased the kernel numbers by $42-77 \%$ (Oury et al., 2016). The heat stress in 15 days from start of silking onwards reduced the kernel numbers by $75 \%$ (Edreira, Carpici, Sammarro, \& Otegui, 2011). Most of current studies has analyzed the impacts on maize kernel number by the heat and drought stresses, but the persistent impact of the stresses around flowering on the subsequent maize kernel development has received limited attention. Furthermore, limited information is available on the individual and combined impacts of heat and drought stress during the early flowering stage on the qualitative aspects in maize grain weight.

For wheat, some studies indicated that the early (around flowering) drought and heat stress shortened leaf area duration (Cristina, Daniel, Calderini, \& Gustavo, 2007), decreased chlorophyll index (Hlaváováet al., 2018) and reduced net photosynthetic rate (Wang, Marija, Dong, Susanne, \& Bernd, 2014). The subsequent impact of early heat stress on grain weight in field was also observed (Abeledo, Savin, \& Slafer, 1999; Calderini, Savin, Abeledo, Reynolds, \& Slafer, 2001; Cristina, Daniel, Calderini, \& Gustavo, 2007). For barley, the heat exposed to booting-anthesis stage decreased grain weight by $13.4 \%$ (Cristina, Daniel, Calderini, \& Gustavo, 2007). For rice, grain yield was reduced by $24 \%$ because of the combined drought and heat stress at anthesis (Amjikarai, Chenniappan, \& Dhashnamurthi, 2018). These observations showed grain development was limited by the source (canopy structure and function), which was affected by the early stress. Whether the sink (grain) development was also limited by the early stress around flowering if source supply was not limited since grain filling remained unclear. Meanwhile, the underlying physiological mechanism for the response of subsequent grain development with both limited and non-limited source supplies to the early heat stress should be further addressed.

It has been generally accepted that the grain weight was determined during the period since grains were actually set (Egli, 2004). Therefore, most studies for grain weight focused on the post-anthesis stage for grain filling (Royo, Abaza, Blanco, García, \& Luis F, 2000). In this study, we hypothesized that the independent and combined drought and heat stress around flowering stage still has significant effect on the subsequent grain filling process even with adequate source supply although the stress was relieved since the beginning of grain filling. The purpose of this study was to (i) detect and compared the impacts of the drought stress, heat stress, and combined drought and heat stress around flowering on the subsequent kernel weight, (ii) compare the response of subsequent grain development to the early stresses with limited source supply in field and adequate source supply in laboratory incubation, (iii) investigate the underlying mechanism of the above responses. This study included three experiments (Figure 1). In Experiment 1 (Exp. 1), maize plants were subjected to drought stress, heat stress and combined drought and heat stress during the short period from tassel emergence to ovaries fertilization in ponds covered with a rain shelter, and the fertilized ovaries continued to grow in field. In Experiment 2 (Exp. 2), the fertilized ovaries in Exp. 1 were vitro cultured in the chamber with favorable growth conditions in laboratory incubation. Sufficient source supply was provided for kernel growth in vitro cultured, which was proved to be an useful method for investigating the grain development (Burle, Gengenbach, Robert, 1994; Zhang et al., 2017). In Experiment 3 (Exp. 3), maize plants were subjected to similar stress with Exp. 1 around flowering in pots, the fertilized ovaries were also vitro cultured for the measurement of carbohydrate metabolism and starch synthesis in grain. Our study reports for the first time about the subsequent impacts of independent and combined drought and heat stress around flowering on maize grain filling and thus necessities the need for development of maize genotypes resilient to these stresses, especially to combined stress environments.

\section{2 | MATERIALS AND METHODS}

\subsection{Experimental site and management}

The Exp. 1 and Exp. 2 was conducted under a half-electric rain shelter at the Shangzhuang Experimental Station of China Agricultural University, Beijing, China, (40 $\left.08^{\prime} \mathrm{N}, 116^{\circ} 10^{\prime} \mathrm{E}\right)$ in 2019. The half-electric rain 
shelter contained 9 big ponds ( $2 \mathrm{~m}$ long, $4 \mathrm{~m}$ wide, and $1.8 \mathrm{~m}$ deep) and 9 small ponds ( $2 \mathrm{~m}$ long, $2 \mathrm{~m}$ wide, and $1.8 \mathrm{~m}$ deep) (Figure 1). Each pond was cemented on the four sides and the bottom, and each pond was filled with soil. The soil was classified as loam. The chemical properties of top $20 \mathrm{~cm}$ soil layer sampled prior to planting was total nitrogen $0.81 \mathrm{~g} \mathrm{~kg}^{-1}$, organic matter $18.88 \mathrm{~g} \mathrm{~kg}^{-1}$, rapid available phosphorus $30.31 \mathrm{mg}$ $\mathrm{kg}^{-1}$, rapid available potassium $100.47 \mathrm{mg} \mathrm{kg}{ }^{-1}$, soil bulk density $1.35 \mathrm{~g} \mathrm{~cm}^{-3}$.

Three seeds (Zhengdan 958) per hole were sowed on May 17, 2019 in each pond and the seedlings were thinned to 7.5 plants $\mathrm{m}^{-2}$ at the 3-leaf stage with a row spacing of $60 \mathrm{~cm}$ and plant spacing of $20 \mathrm{~cm}$. Prior to sowing, $120 \mathrm{~kg} \mathrm{~N} \mathrm{ha}^{-1}, 50 \mathrm{~kg} \mathrm{P}_{2} \mathrm{O}_{5} \mathrm{ha}^{-1}$, and $150 \mathrm{~kg} \mathrm{~K}_{2} \mathrm{O}$ ha $^{-1}$ was applied evenly to the soil surface. The additional $120 \mathrm{~kg} \mathrm{~N} \mathrm{ha}{ }^{-1}$ was applied by furrowing at the 12-leaf stage. Weeds, pests, and diseases were well controlled during the two seasons.

As a pot experiment, Exp. 3 was also conducted at the Shangzhuang Experimental Station in 2016. The same hybrid (Zhengdan 958) was grown in a 120 pots (diameter was $30 \mathrm{~cm}$ at the top and $25 \mathrm{~cm}$ at the bottom, $29 \mathrm{~cm}$ deep). In each pot, $20 \mathrm{~kg}$ naturally air-dried soil that was $1 \mathrm{~cm}$ sieved per pot was filled. The bottoms and inside of pots were perforated with small holes which allow free drainage. The soil was classified as loam. The chemical properties were total nitrogen $0.99 \mathrm{~g} \mathrm{~kg}^{-1}$, organic matter $20.95 \mathrm{~g} \mathrm{~kg}^{-1}$, rapid available phosphorus $24.03 \mathrm{mg} \mathrm{kg}$, rapid available potassium $87.33 \mathrm{mg} \mathrm{kg}^{-1}$, soil bulk density $1.28 \mathrm{~g} \cdot \mathrm{cm}^{-3}$. All the pots were buried in the $25 \mathrm{~cm}$ ditch avoiding high soil temperature. At the commencement of the experiment, fertilizer was applied prior to grown with the amount of $3.9 \mathrm{~g} \mathrm{~N} \mathrm{pot}^{-1}, 12.5 \mathrm{~g} \mathrm{P}_{2} \mathrm{O}_{5}$ pot $^{-1}$, and $5.8 \mathrm{~g} \mathrm{~K}_{2} \mathrm{O} \mathrm{pot}{ }^{-1}$, and then $2.6 \mathrm{~g} \mathrm{pot}^{-1}$ was top-dressed at V12 stage. Four seeds were sown in the central of each plot, at the V3 stage, the five maize seedlings were thinned to one plant per pot.

\section{FIGURE 1}

\subsection{Imposition of the drought and heat stress}

The Exp. 1 was arranged in a completely randomized block design with four replications. The ponds were kept from tasseling to ovaries fertilization under different stress treatments as follows: (I) Well-irrigated in field (CK), the soil potential was $-0.12 \mathrm{MPa}$ (II) Drought stress (DS), introducing a water deficit by no irrigation about $7 \mathrm{~d}$ before tasseling, the soil water potential was -0.51MPa. (III) Heat stress (HS), which was according to the method of Savin, Stone, \& Nicolas (1996). The polyethylene film (100 um thickness) was mounted on steel structures of $3.5 \mathrm{~m}$ height (as showed in Figure 1a), but leaving the bottom $50 \mathrm{~cm}$ of the four sides of each structure open and the top $30 \mathrm{~cm}$ open, in order to facilitate free gas exchange from top to bottom. The magnitude of the elevated canopy air temperature (about 3-5 higher than field) was the consequence of the greenhouse effect of the polyethylene enclosure (Cicchino, Edreira, \& Otegui, 2010). (IV) Combined drought and heat stress (DHS) were realized by the both methods of DS and HS. The soil water potential (depth $40 \mathrm{~cm}$ ) and air temperature (ear position) were recorded by Em50 (Decagon, America) and GSP-6 (Elitech, China), respectively. These sensors of Em50 were buried $40 \mathrm{~cm}$ underground of plot. The effects of stresses in experiment were obvious (Figure 2).

In Exp. 2, the fertilized ears were sampled. According to the methods of Burle, Gengenbach, Robert (1994) and Zhang et al. (2017), husk tissues and silks were gently removed with a fine scalpel blade, taking care to avoid breaking the ovary. Then the superior kernels (basal 18-20 ${ }^{\text {th }}$ line) and inferior kernels (top $3 \mathrm{~cm}$ ) of the ear were sectioned into blocks of $4 \times 4$ (16 grains) and seated into culture media (adequate source supply) in $25 \times 100 \mathrm{~mm}$ Petri dishes such that the media contacted only the cob tissue (Figure. 1e). Kernels were incubated in thermostatic incubator (YIHENG TECH-NICAL.CO., LTD) with 25, relative humidity $75 \%$. To sterilize for 20 minutes with ultraviolet lamp and wipe the inner wall with $75 \%$ ethanol to protect the culture materials from contamination before using thermostatic incubator.

In Exp. 3, the soil moisture regime of 120 pots was $60+-5 \%$ (well-irrigated) of soil water holding capacity before stress treatment. Then the pots were kept from tasseling to ovaries fertilization under different stress treatments as follows: (I) Well-irrigated in field (CK). (II) Drought stress (DS), introducing a water deficit $(30+-5 \%)$ by no irrigation about $7 \mathrm{~d}$ before tasseling. (III) Heat stress (HS), the 30 pots were $60+-5 \%$ (wellwater) of soil water holding capacity also transferred into greenhouse covered with polyethylene film. The 
elevated canopy air temperature (about 3-5 higher than field) was also the consequence of the greenhouse effect of the polyethylene enclosure. (IV) Combined drought and heat stress (DHS) were realized by the both methods of DS and HS. The soil moisture and temperature were recorded by HD2 (IMKO Micromodultechnic GmbH, Germany) and GSP-6 (Elitech, China) during the stress treatment (Figure 2). When the ears were fertilized, the grain was cultured in vitro by the methods of Exp. 2.

\section{FIGURE 2}

\subsection{Sampling and measurements}

\subsubsection{Measurement and sampling in Exp. 1}

Four maize plants were selected in each treatment at the tasseling stage. The maximum length $(\mathrm{L}, \mathrm{cm})$ and real width $(\mathrm{W}, \mathrm{cm})$ of each leaf were measured using the formula (LxWx0.75) to calculate the total plant leaf area. The plant tagged were measured 9 times on DAS (Days after sowing) 61, 66, 75, 82, 89, 99, 108, 118, 123. The SPAD-502 chlorophyll meter was used to monitor chorophyll concentrations (a.u., i.e., SPAD reading) in ear leaf of selected plant. The middle section of the ear leaf was measured 5 times, avoiding the main leaf vein on DAS 59, 64, 69, 75, 82, 89, 99, 108, 118, 123. The net photosynthetic rate of the ear leaf was measured at 10:00-11:00am using Li-CorLI-6400XT Portable Photosynthesis System (Licoln, NE, USA) at DAS 64, 69, 75, 82, 89, 99,108, 123.

Plants growing well were tagged and hand-pollinated by enclosing ears in bags from silk emergence until the last emerged silks became senescent. 200 superior grains (middle grains of spike) and 200 inferior grains (upper grains of spike) from above plants were obtained to determine the grain dry weight at DAS 78, 88, $98,108,118,123$. All grains were dried at 70 to constant weight and weighed. The processes of grain filling were fitted by Logistic growth equation (Figure 3) (Gao et al., 2017):

$\mathrm{W}=\mathrm{K} /\left(1+\mathrm{ae}^{-\mathrm{bt}}\right)$

Where $\mathrm{W}$ is the kernel weight $(\mathrm{mg})$; $\mathrm{K}$ is the final kernel weight $(\mathrm{mg})$; $\mathrm{t}$ is the time after pollination; $\mathrm{a}, \mathrm{b}$ are coefficients determined by regression. The onset time of grain filling peak stage (d): t1=(lna-1.316) $\mathrm{b}^{-1}$; The end time of grain filling peak stage $(\mathrm{d})$ : $\mathrm{t} 2=(\operatorname{lna}+1.316) \mathrm{b}^{-1}$; The end of grain filling $(\mathrm{d})$ : $\mathrm{t} 3=(\ln a+4.595) \mathrm{b}^{-1}$; The slow-increase period (d): $\mathrm{T} 1=\mathrm{t} 1$; The fast-increase period (d): T2=t2-t1; The slight-increase period (d): $\mathrm{T} 3=\mathrm{t} 3$-t2; The mean grain filling rate $\left(\mathrm{mg}_{\text {grain }^{-1}} \mathrm{~d}^{-1}\right): \mathrm{V}=\mathrm{K} \mathrm{t} 3^{-1}$; Mean grain filling rate of slow-increase period $\left(\mathrm{mg}\right.$ grain $\left.{ }^{-1} \mathrm{~d}^{-1}\right)$ : $\mathrm{V} 1=\mathrm{W}_{\mathrm{t} 1} \mathrm{~T}^{-1}$; Mean grain filling rate of fast-increase period $\left(\mathrm{mg} \mathrm{grain}^{-1} \mathrm{~d}^{-1}\right)$ : $\mathrm{V} 2=\left(\mathrm{W}_{\mathrm{t} 2}-\mathrm{W}_{\mathrm{t} 1}\right) \mathrm{T} 2^{-1}$; Mean grain filling rate of slight-increase period $\left(\right.$ mg grain $\left.{ }^{-1} \mathrm{~d}^{-1}\right): \mathrm{V} 3=\left(\mathrm{W}_{\mathrm{t} 3}-\mathrm{W}_{\mathrm{t} 2}\right) \mathrm{T}^{-1}$.

\section{FIGURE 3}

\subsubsection{Sampling in Exp. 2}

Five superior and inferior grains from each treatment were sampled at DAS 78, 88, 98, $108 \mathrm{~d}$ after vitro culture in Exp. 2. All grains were dried at 70 to constant weight and weighed. The kernel weight and grain filling parameters were obtained by methods of Exp. 1.

\subsubsection{Measurements of soluble sugar and starch content in Exp. 3}

The five grains sampled at DAP (Days after pollination) 10, 30, 40 after vitro culture for the measurement of soluble sugar and starch content with the anthrone-sulfuric acid method as follows. The grain pulverized to pass a $1 \mathrm{~mm}$ screen, $1 \mathrm{mg}$ samples were extracted with of $80 \%$ ethanol. Extraction was done three times, followed by centrifugation at $4500 \mathrm{r} / \mathrm{min}$ for $10 \mathrm{~min}$, supernatant was incubated at $100 \operatorname{deg} \mathrm{C}$ for $20 \mathrm{~min}$. The $0.2 \mathrm{~mL}$ supernatant was mixed with $1.25 \mathrm{~mL}$ of Anthron reagent $(100 \mathrm{mg}$ Anthron in $50 \mathrm{~mL}$ sulfuric acid). The mixture was heated in a boiling water for 10 min and cooled in water. OD was measured at 630 nm by using 1510 Microplate Reader (ThermoFisher, Shanghai, China).

The residue of the soluble sugar was mixed with $7 \mathrm{~mL} 3 \mathrm{~mol} \mathrm{~L}^{-1}$ of HCL, then heated in a boiling water for $10 \mathrm{~min}$ and cooled in water, followed by centrifugation at $4500 \mathrm{r} / \mathrm{min}$ for $10 \mathrm{~min}$. The supernatant was mixed with $7 \mathrm{~mL} 3$ of $\mathrm{mol} \mathrm{L}^{-1} \mathrm{NaOH}$ in $50 \mathrm{~mL}$ volumetric flask, and dilute with water to $50 \mathrm{~mL}$. The starch 
content were quantified by using 1510 Microplate Reader (ThermoFisher, Shanghai, China) at a wavelength of $625 \mathrm{~nm}$ after reaction with $0.5 \mathrm{~mL}$ solution from volumetric flask and $2.0 \mathrm{~mL}$ Anthron reagent at $45 \mathrm{oC}$ for $10-15$ min.

\subsubsection{Enzyme activity measurement in Exp. 3}

The methods for enzyme activity of starch synthesis were slightly modified from those described by Nakamura,Yuki, Park, \& Ohya, 1989 and Zinselmeier et al. 1995. Four grains from each treatment were sampled at DAP 10, 25 d after vitro culture in Exp. 3, then frozen in liquid nitrogen for 2 min and stored at -80 for enzyme activity measurements. The extract contained the following: $50 \mathrm{mM}$ Hepes; $2 \mathrm{mM} \mathrm{MgCl}_{2} * 6 \mathrm{H}_{2} \mathrm{O}$; $3 \%(\mathrm{~V} / \mathrm{V})\left(\mathrm{CH}_{2} \mathrm{OH}\right)_{2} ; 1 \mathrm{mM}$ DTT; 1 mM EDTA_-2 $\mathrm{Na} ; 1 \mathrm{~N} \mathrm{NaCl}$.

ADP Glc pyrophosphorylase (EC 2.7.7.27) reaction system: $50 \mathrm{mM}$ Hepes-NaOH (pH 7.2) $100 \mu \mathrm{L} ; 10 \mathrm{mM}$ $\mathrm{MgCl}_{2} \cdot 6 \mathrm{H}_{2} \mathrm{O} 50 \mu \mathrm{L} ; 15 \mathrm{mM}$ DTT $100 \mu \mathrm{L} ; 1.5 \mathrm{mM}$ ADPG $100 \mu \mathrm{L} ; 20 \mathrm{mM}$ PPi $100 \mu \mathrm{L}$; Extract $200 \mu \mathrm{L}$.

Starch synthase (EC 2.4.1.21) reaction system: 50 mM Hepes-NaOH (pH7.2) $50 \mu \mathrm{L} ; 15 \mathrm{mM}$ DTT $50 \mu \mathrm{L} ; 1.5$ $\mathrm{mM}$ ADPG $50 \mu \mathrm{L} ; 1 \mathrm{mg}$ Amylopectin; Extract $200 \mu \mathrm{L}$.

Sucrose invertase (EC 3.2.1.26) reaction system: $\mathrm{CH}_{3} \mathrm{COOH}-\mathrm{CH}_{3} \mathrm{COONa}$ buffer (pH 4.8) $200 \mu \mathrm{L} ; 100 \mathrm{mM}$ Sucrose $200 \mu \mathrm{L}$; Extract $100 \mu \mathrm{L}$.

Sucrose synthase (EC 2.4.1.13) reaction system: 50 mM Hepes-NaOH (pH7.2) $100 \mu \mathrm{L} ; 10 \mathrm{mM}$ UDP $100 \mu \mathrm{L}$; $10 \mathrm{mM} \mathrm{MgCl} 2 \cdot 6 \mathrm{H}_{2} \mathrm{O} 50 \mu \mathrm{L} ; 100 \mathrm{mM}$ Sucrose $150 \mu \mathrm{L}$; Extract $100 \mu \mathrm{L}$.

\subsubsection{Hormone content measurement in Exp. 3}

Four grains from each treatment in Exp. 3 were sampled at DAP 16, $32 \mathrm{~d}$ after vitro culture, then frozen in liquid nitrogen for $2 \mathrm{~min}$ and stored at -80 for $\mathrm{GA}_{3}$, ZR, IAA, ABA measurements. The methods for hormones measurements from those described by Zhang et al. 2009, four frozen grains removed embryos were ground in an ice-cold mortar in $5 \mathrm{~mL} 80 \%$ (V/V) methanol extraction medium containing $1 \mathrm{mM}$ BHT as an antioxidant. The extract was incubated at 4 for $4 \mathrm{~h}$ and centrifuged at $5000 \mathrm{~g}$ for $15 \mathrm{~min}$ at the same temperature. The supernatants were passed through Chromosep $\mathrm{C}^{18}$ columns $\left(\mathrm{C}^{18} \mathrm{Sep}-\mathrm{Pak}\right.$ Cartridge,

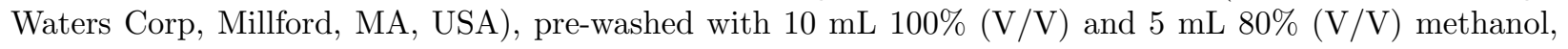
respectively. About $5 \mathrm{~mL}$ purified fraction was collected and dried under $\mathrm{N}_{2}$, and was dissolved in 1.5-3.0 mL phosphate buffer saline containing for analysis by an enzyme-linked immunosorbent assay (ELISA), which was provided by China Agricultural University.

\subsection{Statistical analysis}

All measurements described were comprised of at least 4 biological replicates. Data were separately analyzed for variance using SAS/STAT statistical analysis package (version 6.12, SAS Institute, Cary, NC, USA). Means were tested by least significant difference at the P 0.05 level (LSD 0.05).

\section{3 | RESULTS}

Compared with CK, kernel numbers (KNS) in DS, HS and DHS treatments was all decreased significantly (Figure 4a). The decrease rate of KNS among treatments was in the order of $\mathrm{HS}<\mathrm{DS}<\mathrm{DHS}$. The KNS was decreased by $27 \%, 13 \%, 42 \%$ in DS, HS and DHS treatment, respectively. Furthermore, the subsequent impacts on grain filling of stress episodes around flowering was also observed in both field experiment in Exp. 1 and laboratory incubation experiment through grain vitro culture in Exp. 2 (Figure 4b, c).

\subsection{The response of grain weight to early stress episodes}

For both Exp. 1 in field and Exp. 2 in laboratory, grain weight at physiology maturity in DS, HS and DHS treatments was all decreased significantly compared with CK (Figure 4b, c). Furthermore, the decreased grain weight by the early stresses was observed in both superior and inferior grains. For Exp. 1, the decreased rate of grain weight among treatments was in the order of $\mathrm{HS}<\mathrm{DS}[?] \mathrm{DHS}$ for superior grain and 
DS[?]HS $<$ DHS for inferior grain. Grain weight of superior grain was decreased by $7 \%$ in DS treatment, $5 \%$ in HS treatment and $8 \%$ in DHS treatment. For inferior grain, it was decreased by $6 \%$ in both DS and HS treatments and $11 \%$ in DHS treatment. For Exp. 2, the decreased rate of grain weight among treatments was in the order of DS[?]HS[?]DHS for superior grain and HS<DS[?]DHS for inferior grain. Compared with CK, grain weight of superior grain in DS, HS and DHS treatment was substantially decreased by $34 \%, 35 \%$ and $38 \%$, respectively. Grain weight of inferior grain was decreased by $31 \%$ in DS treatment, $18 \%$ in HS treatment and $32 \%$ in DHS treatment.

\section{FIGURE 4}

\subsection{The dynamic of grain filling process}

The dynamic of grain dry matter accumulation was further investigated in both Exp. 1 and Exp. 2 (Figure 5). At the beginning of grain filling (78 DAS), no significant difference for grain weight (1000-grains weight) was observed among treatments. However, the subsequent grain filling process was significantly impacted by the early stresses for both superior and inferior grains.

\section{FIGURE 5}

In Exp. 1, the decreased grain filling rate and duration mostly occurred in phases I for superior grain (Figure 3 , Table 1). As the most important grain filling period (Phase II, fast-increase period for grain dry matter) (Figure 3), the duration of grain filling in stress treatment was decreased (Table 1). Compared with CK, the growth duration was decreased by 4.7 days in DS treatment, 4.6 days in HS and 2.2 days in DHS treatment. For inferior grains, the response of grain filling was observed in the early stage (Phase I). For Exp. 2, the decreased grain weight in stress treatments was mainly because of the low grain filling rate while the growth duration was even extended for superior grains. During the Phase II, grain filling rate was decreased by $31.1 \%$ in DS treatment, $43.4 \%$ in HS treatment and $42.3 \%$ in DHS treatment. For inferior grains, the decreased grain weight in stress treatments also resulted from the lower grain filling rate compared with CK.

\section{TABLE 1}

\subsection{The leaf area, chlorophyll content, and}

\section{net photosynthesis in stresses}

To identify the source limit to grain weight by the early stresses, the leaf area, relative chlorophyll content (SPAD) and net photosynthesis rate of ear leaves was investigated in field in Exp. 1 (Figure 6). Because of the stresses since 63 DAS, leaf area decreased on 66 DAS in both DS and DHS treatments (Figure 6a). When the stresses were relieved, leaf area recovered for DS treatment on 75 DAS. However, leaf area was consistently lower in stress treatments compared with CK since 89 DAS. The large decrease for leaf area in stress treatments was observed in the middle-late grain filling stage. On 123 DAS (near physiology maturity), the leaf area was decreased by $33 \%$ in DS, $33 \%$ in HS and $36 \%$ in DHS.

The SPAD value was also decreased by the early stress at the middle-late growth stage (from 99 DAS to 123 DAS) (Figure 6b). On 123 DAS, the SPAD value was decreased by $30 \%$ in DS, $38 \%$ in HS and $40 \%$ in DHS. The net photosynthesis rate was significantly reduced when stresses occurred on 69 DAS, but it recovered on 75 DAS when stress was eliminated in both DS and HS treatments (Figure 6c). The net photosynthesis rate continued to be lower in DHS treatment than CK after stress episodes. On 123 DAS, net photosynthesis rate was decreased by $16 \%$ in DS, $13 \%$ in HS and $40 \%$ in DHS. Furthermore, we found the reduction in leaf area, SPAD value, and net photosynthesis rate on 123 DAS compared with CK was in line with the decrease in 1000-kernel weight at physiological maturity (Figure 6d, e, f).

\section{FIGURE 6}

\subsection{The soluble sugar content, starch content, andenzymes activities in grains}

In the laboratory incubation experiment of Exp. 3, the soluble sugar content in both superior and inferior grains reduced with time and remained stable from the $30^{\text {th }}$ day after pollination (DAP) to grain physiology 
maturity (Figure 7a). Similar soluble sugar content was observed among treatments at different stage in both superior and inferior grains with an exception of lower soluble sugar content in DHS treatment on the $10^{\text {th }}$ DAP. For starch content, it showed an increasing trend in both superior grain and inferior grains with time. In stress treatments, starch content in grain was significantly lower compared with CK. On the $40^{\text {th }} \mathrm{DAP}$, it was reduced by $12 \%$ in DS, $12 \%$ in HS, and $9 \%$ in DHS for superior grains.

\section{FIGURE 7}

The activities of the four enzymes in relation to starch synthesis in grain exhibited variable responses to stresses (Figure 8). Compared with CK, sucrose invertase activity was decreased by $30 \%$ in DS, $41 \%$ in HS and $30 \%$ in DHS on the $10^{\text {th }}$ DAP for superior grain. For inferior grain, it was reduced by $57 \%$ in DS, $40 \%$ in HS and $51 \%$ in DHS. Similar or even higher sucrose invertase activity was observed on the $25^{\text {th }}$ DAP in stress treatments (Figure 8a). For sucrose synthase activity, it was decreased by $30-45 \%$ on the $10^{\text {th }}$ DAP and by $28-39 \%$ on the $25^{\text {th }}$ DAP for superior grain in stress treatments. For inferior grain, it was decreased by $19-21 \%$ on the $10^{\text {th }}$ DAP in stress treatments (Figure $8 b$ ). For ADP Glc pyrophosphorylase activity, it was decreased by $21-67 \%$ on the $10^{\text {th }}$ DAP and by $16-50 \%$ on the $25^{\text {th }}$ DAP for superior grain in the stress treatments compared with CK. For inferior grain, lower ADP Glc pyrophosphorylase activity was observed in both DS and DHS treatments (Figure 8c). For starch synthase activity, it was decreased by $22-34 \%$ on the $10^{\text {th }}$ DAP in stress treatment for superior grain (Figure $8 \mathrm{~d}$ ).

\section{FIGURE 8}

\subsection{The hormone content in grains}

In Exp. 3, the hormone contents related to grain filling changed with time in different treatments (Figure 9 ). Correlation analysis indicated that the average of grain filling rate was negatively correlated with the ZR content in both superior and inferior grains (Table 2). Compared with CK, ZR content was increased by $11 \%$ in DHS treatment on the $16^{\text {th }}$ DAP for superior grain (Figure 9a). It was increased by $19 \%$ in DS treatment, $20 \%$ in HS treatment and $16 \%$ in DHS treatment on the $16^{\text {th }}$ DAP for inferior grain. The mean grain filling rate was positively correlated with the IAA content in superior grains on the $32^{\text {th }}$ DAP. For IAA content, it was reduced by $21 \%$ in DS treatment, $26 \%$ in HS treatment and $20 \%$ in DHS treatment on the $32^{\text {th }}$ DAP for superior grain (Figure $9 \mathrm{~b}$ ).

\section{FIGURE 9}

\section{TABLE 2}

\section{4 | DISCUSSION}

We found the negative effects of DS, HS and DHS around flowering on maize grain filling. The early stress around flowering reduced kernel weight by shortened grain filling duration, accelerated leaf senescence, and decreased net photosynthesis in field condition. When the source supply was sufficient by vitro cultured in laboratory incubation, the early stress still significantly decreased kernel weight. These results clearly showed that the independent and combined drought and heat stress around flowering stage had significant impact on the subsequent grain filling even with sufficient source supply (Figure 10).

\section{FIGURE 10}

\subsection{The reduced grain weight in field}

Drought and heat stress are two main factors adversely affecting crop productivity. In the present study, the grain weight was decreased by $6-7 \%$ in DS treatment, $5-6 \%$ in HS treatment and $8-11 \%$ in DHS treatment under field condition (Figure 4), which was consistent with the previous reports (Jones, Roessler, \& Ouattar, 1985; Westgate et al., 1994).

Multiple underlying mechanisms may contribute to the reduced grain weight in stresses in field. From a source (leaf) perspective, the drought and heat stress accelerated leaf senescence and decreased photosynthetic capacity (Hlaváová et al., 2018; Zhou, Zhou, He, Zhou, \& Zhou, 2019). In this study, we found the leaf area 
and SPAD were decreased by the early stress at the middle-late growth stage (from 99 DAS to 123 DAS) (Figure 6a, b). The net photosynthesis rate was decreased by $16 \%$ in DS treatment, $13 \%$ in HT treatment and $40 \%$ in DHS treatment on DAS 123 (Figure 6c). The inhibited leaf photosynthesis mainly resulted from the decrease of maximum photosynthetic electron transport rate and carboxylation efficiency (Wang et al., 2015). Furthermore, grain weight was reduced because the grain filling period was short in stresses (Chen et al., 2013; Mayer, Rattalino, \& Maddonni, 2014; Plaut, Butow, Blumenthal, \& Wrigley, 2004). Grain filling duration of superior grains was decreased by 4.7 days in DS treatment, 4.6 days in HS treatment and 2.2 days in DHS treatment at fast-increase period (Table 1). The results above showed that DS, HS and DHS treatment around flowering could shorten grain filling duration in superior grain, without sufficient increases in grain filling rate to compensate, resulted in grain weight reduction, which was inconsistent with previous researches (Jones, Roessler, \& Ouattar, 1985; Yang et al., 2006). Some studies also showed that the drought and heat stress shortened the grain filling period, but the grain weight could be compensated by faster grain filling rate, enhanced pre-stored carbohydrate remobilization, and accelerated endosperm cell division (Jones, Roessler, \& Ouattar, 1985; Yang \& Zhang, 2006).

\subsection{Grain development in laboratory incubation}

The grain weight in vitro cultured incubation was still decreased largely by $18-38 \%$ in the stress treatments (Figure 4). This result showed the impacts of stresses exposed around flowering persisted when the sufficient source supply was provided. Through the dynamic of grain weight, we found the early stress did not shorten grain filling period, but the mean grain filling rate was reduced by $13-40 \%$ (Table 1 ).

Maize kernel development is mainly a process of carbohydrate metabolism and starch synthesis (Singletary, Banisadr, \& Keeling, 1997). Some studies demonstrated that lack of assimilates within the embryo or endosperm limited maize kernel development in drought during grain filling stage (Westgate et al., 1994). In this study, the soluble sugar used to starch synthesis in the stress was relatively high (Figure 7a), suggested that the carbohydrate metabolism was not the main factor affecting final kernel weight. This was agreement with previous research in maize under water deficit (Oury, Tardieu, \& Turc, 2016; Oury et al., 2016). However, the starch content of grain was significantly decreased in the DS, HS and DHS treatment (Figure 7b), indicating the sugar-to-starch synthesis was interfered in stresses during maize grain development (Jones et al., 1985; Singletary, Banisadr, \& Keeling, 1994; Zinselmeier, \& C, 1999).

Grain weight was reduced because the starch biosynthesis in endosperm cell was interfered in stress (Jones, Roessler, \& Ouattar, 1985). Meanwhile, the rate of endosperm cell division was decreased with reduced starch granules in stress during maize seed development (Singletary, Banisadr, \& Keeling, 1994). The enzymes activities for starch biosynthesis (surcose invertase, sucrose synthase, ADP Glc pyrophosphorylase and starch synthase) played a key role in this process (Figure 10). First, previous reports showed the sucrose invertase produced adequate glucose and fructose to allow grain set to proceed (Ruan, Jin, Yang, Li, \& Boyer, 2010). In this study, sucrose invertase activity in grain was decreased by $30-57 \%$ in stress treatments on the early grain filling stage on $10^{\text {th }}$ DAP for superior grain (Figure 8a). Second, the sucrose synthase catalysed the cleavage of sucrose to form UDPG and fructose, and its activity was linked to sink strength in development grain (Kato, 1995; Yang, Zhang, Wang, Xu, \& Zhu, 2004). The activity of sucrose synthase was decreased by 30-45\% on the $10^{\text {th }}$ DAP for superior grain in stress treatments (Figure $8 \mathrm{~b}$ ). Third, the ADP Glc pyrophosphorylase produced ADPG, which was the primer of the starch chain regarded as the rate-limiting enzyme in starch biosynthesis (Preiss, 1988; Smith and Denyer, 1992; Yang, Zhang, Wang, Xu, \& Zhu, 2004). The activity of ADP Glc pyrophosphorylase was decreased by $21-67 \%$ on the $10^{\text {th }}$ DAP and by $16-50 \%$ on the $25^{\text {th }}$ DAP for superior grain in the stress treatments compared with CK (Figure 8c). Finally, the previous found the starch synthase activity is positively correlated with the rate of starch synthesis (Keeling, Bacon, \& Holt, 1993; Nakamura and Yuki, 1992). We also found starch synthase activity was decreased by 22-34\% on the $10^{\text {th }}$ DAP in stress treatments for superior grain (Figure $8 \mathrm{~d}$ )

The starch synthesis is not only affected by enzymes activity but also regulated by hormone content. It was reported that the content of $\mathrm{Z}+\mathrm{ZR}$ and IAA in rice grains was related to the endosperm cell division and starch biosynthesis (Huang et al., 2016; Zhang et al., 2009). The DS, HS and DHS around flowering 
increased ZR content by $11-20 \%$ in superior and inferior grains on $16^{\text {th }}$ and $32^{\text {th }}$ DAP (Figure 9a). The correlation analysis showed the mean grain filling rate was negatively correlated with the ZR content in both superior and inferior grains (Table 2). For IAA content, it was reduced by $20-26 \%$ in stress treatments on the $32^{\text {th }}$ DAP for superior grain (Figure $9 \mathrm{~b}$ ). The IAA content was positively correlated with grain filling rate in superior grains at $32^{\text {th }}$ DAP (Table 2). The IAA content mainly increased grain development in mid-grain filling, which was consistent with previous study (Yang, Zhang, Wang, Zhu, \& Wang, 2001). In this paper, the $\mathrm{ABA}$ and $\mathrm{GA}_{3}$ contents were also changed by DS, HS and DHS treatment around flowering (Figure 9c, d), however, there was no significant correlation with the mean grain filling rate (Table 2). The previous researches reported that the grain filling rate was closely associated with an enhanced ABA level in water-stressed grains (Yang, Zhang, Wang, Zhu, \& Wang, 2001; Yang, Zhang, Wang, Xu, \& Zhu, 2004). In addition, the GAs content was associated with the development of embryo at early grain filling stage (Schussler, Brenner, \& Brun, 1991).

\subsection{The implication for maize breeding}

In this study, we found the subsequent impacts on grain filling of stresses episodes around flowering mainly resulted from the disturbing starch synthesis. Therefore, maize hybrids that have a high ability for starch synthesis in kernel are likely more tolerant to DS, HS and DHS. This should be received more attention in future breeding program. For example, the drought-tolerant lentil showed stronger ability of starch synthesis in seeds (Sehgal et al., 2018). Meanwhile, we found the grain weight was also reduced by shortened grain filling duration, accelerated leaf senescence, and decreased photosynthesis in field. This also implicated the importance of delaying senescence and improving photosynthetic capacity for maize breeding. For example, the drought-tolerant hybrid maintained greater photosynthetic rates $(+8-10 \%)$ compared with the conventional hybrid (Lindsey, Barker, Metzger, Mullen, \& Thomison, 2018). Meanwhile, the heat-tolerant germplasm emphasized the importance of sufficient $\mathrm{CO}_{2}$ exchange rate (Neiff, Trachsel, Valentinuz, Balbi, \& Andrade, 2016).

\section{5 | CONCLUSION}

The study showed that the negative effects of the stress around flowering persisted in the kernel. In field, the accelerated leaf senescence and decreased net photosynthesis rate was observed. Although the supply of source was sufficient in vitro cultured in the chamber, the effect of stresses imposed around flowering on kernel weight was inevitable. The kernel weight reduction mainly resulted from decreasing enzyme activities related to starch synthesis, which further reduced grain filling rate. It is necessary to further investigate the effect of the early stresses on kernel through the view of key proteins and genes. This information is important for breeding and selecting stress tolerant maize hybrids.

\section{ACKNOWLEDGEMENTS}

This work was supported by the National Science Foundation of China (Grant No. 31571592) and the National Key Research and Development Program of China (2017YFD0300410). We thank the anonymous reviewers and Handling Editors for constructive inputs and suggestions. Xiwei Liu gratefully acknowledges inputs from Xin Wang on an earlier version of the manuscript.

\section{CONFLICT OF INTEREST}

The authors declare no conflict of interest.

\section{AUTHORS CONTRIBUTION}

The work was envisioned by Qingfeng Meng, Shoubing Huang and Pu Wang jointly led the research. Xiwei Liu wrote the manuscript with primary support from Qingfeng Meng. Guanying Chen was responsible for collecting data from Exp. 3. Chenchen Xu, Yonghong Yu and Jia Gao participated in the acquisition of experimental data. Xingya Wang contribution to analysis and interpretation of data. All co-authors commented on the manuscript.

\section{REFERENCES}


Abeledo L.G., Savin R. \& Slafer G. A. (1999). Effect of temperature and carpel size during pre-anthesis on potential grain weight in wheat.Journal of Agricultural Science, 132(6), 453-459

Alam M.A., Seetharam K., Zaidi P.H., Dinesh A., Vinayan M.T. \& Nath U.K. (2017). Dissecting heat stress tolerance in tropical maize (Zea mays L.). Field Crops Research, 204, 110-119

Amjikarai R.N.K., Chenniappan V. \& Dhashnamurthi V. (2018). Combined effects of drought and moderately high temperature?on the photosynthesis, ps ii photochemistry and yield traits in rice (oryza sativa 1.). Indian Journal of Plant Physiology.https:// doi:10.1007/s40502-018-0386-4

Bassetti P. \& Westgate M.E. (1993). Water deficit affects receptivity of maize silks. Crop Science, 33(2)

Burle G. Gengenbach, \& Robert J. Jones. (1994). In vitro Culture of Maize Kernels. The Maize Handbook. Springer New York.

Bonfante A., Monaco E., Alfieri S.M., De L.F., Manna P., Basile A. \& Bouma J. (2015). Climate change effects on the suitability of an agricultural area to maize cultivation: application of a new hybrid land evaluation system. In Advances in Agronomy, 133, 33-69

Calderini D.F., Savin R., Abeledo L.G., Reynolds M.P. \& Slafer G.A. (2001). The importance of the period immediately preceding anthesis for grain weight determination in wheat. Euphytica, 119(1-2), 199-204

Cristina U., Daniel F., Calderini \& Gustavo A.S. (2007). Grain weight and grain number responsiveness to pre-anthesis temperature in wheat, barley and triticale. Field Crops Research, 100(2-3), 240-248

Cicchino M., Edreira J.I. \& Otegui M.E. (2010). Heat stress during late vegetative growth of maize: effects on phenology and assessment of optimum temperature. Crop science, 50(4), 1431-1437

Chen T., Xu Y., Wang J., Wang Z., Yang J. \& Zhang J. (2013). Polyamines and ethylene interact in rice grains in response to soil drying during grain filling. Journal of experimental botany, 64(8), 2523-2538

Dai A., Trenberth K.E., \& Qian T. (2004). A global dataset of Palmer Drought Severity Index for 1870-2002: Relationship with soil moisture and effects of surface warming. Journal of Hydrometeorology,5(6), 1117-1130

Dresselhaus T. \& Franklin-Tong N. (2013). Male-female crosstalk during pollen germination, tube growth and guidance, and double fertilization.Molecular plant, 6(4), 1018-1036.

Egli D.B. (2004). Seed-fill duration and yield of grain crops.Advance in Agronomy, 83, 243-279.

Edreira J.I.R., Carpici E.B., Sammarro D. \& Otegui M.E. (2011). Heat stress effects around flowering on kernel set of temperate and tropical maize hybrids. Field Crops Research, 123(2), 62-73

Gao Z., Liang X.G., Zhang L., Lin S., Zhao X., Zhou L.L., Shen S. \& Zhou S.L. (2017). Spraying exogenous 6 -benzyladenine and brassinolide at tasseling increases maize yield by enhancing source and sink capacity. Field Crops Research.

Harrison M.T., Tardieu F., Dong Z., Messina C.D. \& Hammer G.L. (2014). Characterizing drought stress and trait influence on maize yield under current and future conditions. Global change biology, 20(3), 867-878

Huang H., Xie S., Xiao Q., Wei B., Zheng L., Wang Y. \& Hu Y. (2016). Sucrose and ABA regulate starch biosynthesis in maize through a novel transcription factor, zmEREB156. Scientific reports, 6, 27590

Hlavaova M., Klem K., Rapantova B., Novotna K., Urban O. \& Hlavinka P. (2018). Interactive effects of high temperature and drought stress during stem elongation, anthesis and early grain filling on the yield formation and photosynthesis of winter wheat. Field Crops Research, 221, 182-195

Jones, R. J., Roessler, J., \& Ouattar, S. (1985). Thermal Environment During Endosperm Cell Division in Maize: Effects on Number of Endosperm Cells and Starch Granules 1. Crop Science, 25(5) , 830-834

Keeling, P. L., Bacon, P. J., \& Holt, D. C. (1993). Elevated temperature reduces starch deposition in wheat endosperm by reducing the activity of soluble starch synthase. Planta, 191(3), 342-348 
Kato T. (1995). Change of sucrose synthase activity in developing endosperm of rice cultivars. Crop Science, 35(3) , 827-831.

Lesk C, Rowhani P. \& Ramankutty N. (2016). Influence of extreme weather disasters on global crop production. Nature, 529(7584), 84-87.

Lindsey A.J., Barker D.J., Metzger J.D., Mullen R.W. \& Thomison P.R. (2018). Physiological and morphological response of a drought-tolerant maize hybrid to agronomic management. Agronomy Journal , 110(4), $1354-$.

Lizaso J.I., Ruiz-Ramos M., L. Rodriguez, Gabaldon-Leal C., Oliveir J.A. \& Lorite I.J. (2018). Impact of high temperatures in maize: phenology and yield components. Field Crops Research, 216, 129-140

Marceau A., Saint-Jean S., Loubet B., Foueillassar X. \& Huber L. (2012). Biophysical characteristics of maize pollen: variability during emission and consequences on cross-pollination risks. Field Crops Research, 127(1), 51-63

Mayer L.I., Rattalino Edreira, J.I. \& Maddonni G.A. (2014). Oil yield components of maize crops exposed to heat stress during early and late grain-filling stages. Crop Science, 54(5), 2236-2250

Nakamura Y., Yuki K., Park S.Y. \& Ohya T. (1989). Carbohydrate metabolism in the developing endosperm of rice grains. Plant and cell physiology, 30(6), 833-839.

Nakamura Y. \& Yuki K. (1992) Changes in enzyme activities associated with carbohydrate metabolism during development of rice endosperm. Plant Science, 82, 15-20

Neiff Nicolas, Trachsel S., Valentinuz O.R., Balbi C.N. \& Andrade F.H. (2016). High temperatures around flowering in maize: effects on photosynthesis and grain yield in three genotypes. Crop Science,56(5), 2702

Oury V., Tardieu F. \& Turc O. (2016). Ovary apical abortion under water deficit is caused by changes in sequential development of ovaries and in silk growth rate in maize. Plant Physiology, 171(2), 986-996

Oury V., Caldeira C.F., Prodhomme D., Pichon J.P., Gibon Y., Tardieu F. \& Turc O. (2016). Is change in ovary carbon status a cause or a consequence of maize ovary abortion in water deficit during flowering?.Plant physiology, 171(2), 997-1008

Preiss J. (1988). Biosynthesis of starch and its regulation. The biochemistry of plants, 14, 181-254

Plaut Z., Butow B.J., Blumenthal C.S. \& Wrigley C.W. (2004). Transport of dry matter into developing wheat kernels and its contribution to grain yield under post-anthesis water deficit and elevated temperature.Field Crops Research, 86(2-3), 185-198.

Royo C., Abaza M., Blanco R. \& Garcia del Moral, Luis F. (2000). Triticale grain growth and morphometry as affected by drought stress, late sowing and simulated drought stress. Functional Plant Biology, 27(11), 1051

Ruan Y.L., Jin Y., Yang Y.J., Li G.J. \& Boyer J.S. (2010). Sugar input, metabolism, and signaling mediated by invertase: roles in development, yield potential, and response to drought and heat. Molecular Plant, 3(6), 942-955

Rossini M.A., Maddonni G.A. \& Otegui M.E. (2016). Multiple abiotic stresses on maize grain yield determination: additive vs multiplicative effects. Field Crops Research, 198, 280-289

Schussler J.R., Brenner M.L. \& Brun W.A. (1991). Relationship of endogenous abscisic acid to sucrose level and seed growth rate of soybeans. Plant Physiology, 96(4), 1308-1313

Smith A.M. \& Denyer K.A.Y. (1992). Starch synthesis in developing pea embryos. New phytologist, 122(1), $21-33$ 
Singletary G.W., Banisadr R. \& Keeling P.L. (1994). Heat stress during grain filling in maize: effects on carbohydrate storage and metabolism. Functional Plant Biology, 21.

Savin R., Stone P. \& Nicolas M. (1996). Responses of grain growth and malting quality of barley to short periods of high temperature in field studies using portable chambers. Australian Journal of Agricultural Research, 47(3), 465

Singletary G.W., Banisadr R. \& Keeling P. L. (1997). Influence of gene dosage on carbohydrate synthesis and enzymatic activities in endosperm of starch-deficient mutants of maize. Plant physiology, 113(1), 293-304

Sheffield J., Wood E.F. \& Roderick M.L. (2012). Little change in global drought over the past 60 years. Nature, 491(7424), 435-438

Sanchez B., Rasmussen A. \& Porter J.R. (2014). Temperatures and the growth and development of maize and rice: a review. Global change biology, 20(2), 408-417.

Sehgal A., Sita K., Bhandari K., Kumar S., Kumar J. \& Vara Prasad P.V. (2018). Influence of drought and heat stress, applied independently or in combination during seed development, on qualitative and quantitative aspects of seeds of lentil ( $\backslash \mathrm{r}$, lens culinaris $\backslash \mathrm{r}$, medikus) genotypes, differing in drought-sensitivity. Plant Cell E Environment.https://doi:10.1111/pce.13328

Shen S., Zhang L., Liang X.G., Zhao X., Lin S., Qu L.H. \& Zhou S.L. (2018). Delayed pollination and low availability of assimilates are major factors causing maize kernel abortion. Journal of experimental botany, 69(7), 1599-1613

Westgate M.E. (1994). Water status and development of the maize endosperm and embryo during drought.Crop Science, 34(1), 76-83

Wilhelm E.P., Mullen R.E., Keeling P.L. \& Singletary G.W. (1999). Heat stress during grain filling in maize: effects on kernel growth and metabolism. Crop science, 39(6), 1733-1741

Waha K., Muller C. \& Rolinski S. (2013). Separate and combined effects of temperature and precipitation change on maize yields in sub-saharan africa for mid- to late-21st century. Global and Planetary Change, 106, $1-12$

Wang X., Marija V., Dong J., Susanne J. \& Bernd W. (2014). Improved tolerance to drought stress after anthesis due to priming before anthesis in wheat (triticum aestivum 1.) var. vinjett. Journal of Experimental Botany, 65, 22

Wang Q., Wu J., Lei T., He B., Wu Z., Liu M. \& Liu D. (2014). Temporal-spatial characteristics of severe drought events and their impact on agriculture on a global scale. Quaternary International, 349, 10-21

Wang Z., Xu Y., Chen T., Zhang H, Yang J. \& Zhang J. (2015). Abscisic acid and the key enzymes and genes in sucrose-to-starch conversion in rice spikelets in response to soil drying during grain filling.Planta, 241(5), 1091-1107

Wang X., Vignjevic M., Liu F., Jacobsen S., Jiang D. \& Wollenweber B. (2015). Drought priming at vegetative growth stages improves tolerance to drought and heat stresses occurring during grain filling in spring wheat. Plant Growth Regulation, 75(3), 677-687

Wang L, Liao S., Huang S., Ming B., Meng Q. \& Wang P. (2018). Increasing concurrent drought and heat during the summer maize season in Huang-Huai-Hai Plain, China. International Journal of Climatology, $38(7), 3177-3190$

Yang J., Zhang J., Wang Z., Zhu Q. \& Wang W. (2001). Hormonal changes in the grains of rice subjected to water stress during grain filling.Plant physiology, 127(1), 315-323

Yang J., Zhang J., Wang Z., Xu G. \& Zhu Q. (2004). Activities of key enzymes in sucrose-to-starch conversion in wheat grains subjected to water deficit during grain filling. Plant physiology, 135(3), 1621-1629 
Yang J. \& Zhang J. (2006). Grain filling of cereals under soil drying.New phytologist, 169(2), 223-236

Zinselmeier C., Westgate M.E., Schussler J.R. \& Jones R.J. (1995). Low water potential disrupts carbohydrate metabolism in maize (Zea mays L.) ovaries. Plant Physiology, 107(2), 385-391

Zinselmeier, \& C. (1999). Starch and the control of kernel number in maize at low water potentials. Plant Physiology, 121(1), 25-36.

Zhang H., Tan G., Yang L., Yang J., Zhang J. \& Zhao B. (2009). Hormones in the grains and roots in relation to post-anthesis development of inferior and superior spikelets in japonica/indica hybrid rice.Plant Physiology and Biochemistry, 47(3), 195-204

Zhang P., Chen G.Y., Geng P., Gao Y., Zheng L., Zhang S.S., Wang P. (2017). Effects of high temperature during grain filling period on superior and inferior kernels' development of different heat sensitive maize varieties. Scientia Agricultura Sinica, 2017, 50 (11), 2061-2070.

Zhou H., Zhou G., He Q., Zhou L., \& Zhou M. (2019). Environmental explanation of maize specific leaf area under varying water stress regimes. Environmental and Experimental Botany, 171

\section{Figure legends}

FIGURE 1 (a) Partial view of Exp. 1 and Exp. 2 with the drought and heat stress, with a detail on how the system looked like from inside the enclosures. (b) Partial view of Exp.3 with the drought and heat stress, with a detail on how the system looked like from inside the enclosures. (c) The stage exposed to drought, heat and combined drought and heat stress for each treatment. (d) The growth conditions in Exp.1. (e) Processing of maize grains cultivation in vitro in Exp. 2 and Exp. 3. CK, control treatment. DS, drought stress treatment. HS, heat stress treatment. DHS, combined drought and heat stress treatment.

FIGURE 2 (a) Time courses of average soil water potential and temperature in Exp. 1 and Exp. 2. (b) Time courses of soil water content and temperature in Exp. 3. CK, control treatment. DS, drought stress treatment. HS, heat stress treatment. DHS, combined drought and heat stress treatment.

FIGURE 3 Schematic diagram of logistic curve (black color), where $\mathrm{W}$ is the kernel weight (mg), $\mathrm{K}$ is the final kernel weight $(\mathrm{mg}), \mathrm{t}$ is the time after pollination. $\mathrm{a}, \mathrm{b}$ are coefficients determined by regression. Phase I: The slow-increase period (d); Phase II: The fast-increase period (d); Phase III: The slight-increase period (d).

FIGURE 4 Effects of drought, heat and combined drought and heat stress around flowering on kernel numbers and 1000-kernels weight at physiological maturity. (a) The kernel numbers in Exp. 1. (b) The 1000-kernels weight in Exp.1. (c) The 1000-kernels weight in Exp. 2. Values with the same letter are not significantly different at $P<0.05$ within the same parameter of each hybrid. Bars denote the standard error of the mean $(n=4)$. CK, control treatment. DS, drought stress treatment. HS, heat stress treatment. DHS, combined drought and heat stress treatment.

FIGURE 5 Effect of drought, heat and combined drought and heat stress around flowering on grain dry matter accumulation. (a) The changes of 1000-kernels weight in superior and inferior grains in Exp. 1. (b) The 1000-kernels weight in superior and inferior grains in Exp. 2. Values with the same letter are not significantly different at $P<0.05$ within the same parameter of each hybrid. Bars denote the standard error of the mean $(\mathrm{n}=4)$. CK, control treatment. DS, drought stress treatment. HS, heat stress treatment. DHS, combined drought and heat stress treatment.

FIGURE 6 Effect of drought, heat and combined drought and heat stress around flowering on leaf area, SPAD and net photosynthesis $\left(\mathrm{Pn} ; \mu \mathrm{mol} \mathrm{CO} \mathrm{CO}^{-2} \mathrm{~s}^{-1}\right.$ ). (a) The changes of leaf area in Exp.1. (b) The changes of SPAD in Exp.1. (c) The changes of net photosynthesis in Exp.1. (d) The relationship between 1000-kernel weight and leaf area reduction at maturity. (e) The relationship between 1000-kernel weight and SPAD reduction at maturity. (f) The relationship between 1000-kernel weight and net photosynthesis reduction at maturity. Values with the same letter are not significantly different at $\mathrm{P}<0.05$ within the same 
parameter of each hybrid. Bars denote the standard error of the mean $(n=4)$. CK, control treatment. DS, drought stress treatment. HS, heat stress treatment. DHS, combined drought and heat stress treatment.

FIGURE 7 The soluble sugar content and starch content in superior and inferior grains under drought, heat and combined drought and heat stress around flowering. (a) The changes of soluble sugar in Exp. 3. (b) The changes of starch content in Exp. 3. Values with the same letter are not significantly different at $\mathrm{P}<0.05$ within the same parameter of each hybrid. Bars denote the standard error of the mean $(\mathrm{n}=4)$. CK, control treatment. DS, drought stress treatment. HS, heat stress treatment. DHS, combined drought and heat stress treatment.

FIGURE 8 Enzymes activity related to starch synthesis in superior grains and inferior grains under drought, heat and combined drought and heat stress around flowering in Exp. 3. (a) The sucrose invertase activity in superior and inferior grains. (b) The sucrose synthase activity in superior and inferior grains. (c) The ADP Glc pyrophosphorylase activity in superior and inferior grains. (d) The starch synthase activity in superior and inferior grains. Values with the same letter are not significantly different at $P<0.05$ within the same parameter of each hybrid. Bars denote the standard error of the mean $(n=4)$. CK, control treatment. DS, drought stress treatment. HS, heat stress treatment. DHS, combined drought and heat stress treatment.

FIGURE 9 Hormone content in superior grains and inferior grains under drought, heat and combined drought and heat stress around flowering in Exp. 3. (a) The ZR content in superior and inferior grains. (b) The IAA content in superior and inferior grains. (c) The $\mathrm{GA}_{3}$ content in superior and inferior grains. (d) The ABA content in superior and inferior grains. Values with the same letter are not significantly different at $\mathrm{P}<0.05$ within the same parameter of each hybrid. Bars denote the standard error of the mean $(\mathrm{n}=4)$. CK, control treatment. DS, drought stress treatment. HS, heat stress treatment. DHS, combined drought and heat stress treatment.

FIGURE 10 A schematic diagram of how drought, heat and combined drought and heat stress around flowering reduced kernel weigh. CK: control treatment; DS: drought stress treatment; HS: heat stress treatment; DHS: combined drought and heat stress treatment. Solid line indicated superior grain. Dotted line represented the inferior grain. The three lines from left to right represent DS, HS and DHS stress. The line thickness represents the influence degree of stresses.

\section{Table legends}

TABLE 1 Grain filling parameters under the condition of drought, heat and combined drought and heat stress around flowering in Exp. 1 and Exp. 2.

TABLE 2 Correlations of hormonal content in superior and inferior grains with mean grain filling rate at 86 and 102 days after pollination.

\section{Hosted file}

image1.emf available at https://authorea.com/users/322706/articles/451657-the-subsequentimpacts-of-independent-and-combined-drought-and-heat-stress-around-flowering-on-maizegrain-filling-field-and-laboratory-investigation

\section{FIGHRE 1}

\section{Hosted file}

image2.emf available at https://authorea.com/users/322706/articles/451657-the-subsequentimpacts-of-independent-and-combined-drought-and-heat-stress-around-flowering-on-maizegrain-filling-field-and-laboratory-investigation

\section{FIGURE 2}

\section{Hosted file}


image3.emf available at https://authorea.com/users/322706/articles/451657-the-subsequentimpacts-of-independent-and-combined-drought-and-heat-stress-around-flowering-on-maizegrain-filling-field-and-laboratory-investigation

\section{FIGURE 3}

\section{Hosted file}

image4.emf available at https://authorea.com/users/322706/articles/451657-the-subsequentimpacts-of-independent-and-combined-drought-and-heat-stress-around-flowering-on-maizegrain-filling-field-and-laboratory-investigation

\section{FIGURE 4}

\section{Hosted file}

image5.emf available at https://authorea.com/users/322706/articles/451657-the-subsequentimpacts-of-independent-and-combined-drought-and-heat-stress-around-flowering-on-maizegrain-filling-field-and-laboratory-investigation

\section{FIGURE 5}

\section{Hosted file}

image6.emf available at https://authorea.com/users/322706/articles/451657-the-subsequentimpacts-of-independent-and-combined-drought-and-heat-stress-around-flowering-on-maizegrain-filling-field-and-laboratory-investigation

\section{FIGURE 6}

\section{Hosted file}

image7.emf available at https://authorea.com/users/322706/articles/451657-the-subsequentimpacts-of-independent-and-combined-drought-and-heat-stress-around-flowering-on-maizegrain-filling-field-and-laboratory-investigation

\section{FIGURE 7}

\section{Hosted file}

image8.emf available at https://authorea.com/users/322706/articles/451657-the-subsequentimpacts-of-independent-and-combined-drought-and-heat-stress-around-flowering-on-maizegrain-filling-field-and-laboratory-investigation

\section{FIGURE 8}

\section{Hosted file}

image9.emf available at https://authorea.com/users/322706/articles/451657-the-subsequentimpacts-of-independent-and-combined-drought-and-heat-stress-around-flowering-on-maizegrain-filling-field-and-laboratory-investigation

\section{FIGURE 9}

\section{Hosted file}

image10.emf available at https://authorea.com/users/322706/articles/451657-the-subsequentimpacts-of-independent-and-combined-drought-and-heat-stress-around-flowering-on-maizegrain-filling-field-and-laboratory-investigation

\section{FIGURE 10}


TABLE 1 Grain filling parameters under the condition of drought, heat and combined drought and heat stress around flov

Parameters

Exp. 1

Phase I (days)

Phase II (days)

Phase III (days)

Total Phase (days)

V1 (mg grain $\left.{ }^{-1} \mathrm{~d}^{-1}\right)$

V2 $\left(\right.$ mg grain $\left.{ }^{-1} \mathrm{~d}^{-1}\right)$

V3 (mg grain $\left.{ }^{-1} \mathrm{~d}^{-1}\right)$

$\mathrm{V}\left(\mathrm{mg}\right.$ grain $\left.^{-1} \mathrm{~d}^{-1}\right)$

Exp. 2

Phase I (days)

Phase II (days)

Phase III (days)

Total Phase (days)

V1 $\left(\mathrm{mg}_{\text {grain }}^{-1} \mathrm{~d}^{-1}\right)$

V2 $\left(\mathrm{mg}\right.$ grain $\left.^{-1} \mathrm{~d}^{-1}\right)$

V3 $\left(\mathrm{mg}\right.$ grain $\left.^{-1} \mathrm{~d}^{-1}\right)$

$\mathrm{V}\left(\mathrm{mg}\right.$ grain $\left.^{-1} \mathrm{~d}^{-1}\right)$

Note: Phase I: Slow-increase period; Phase II: Fast-increase period; Phase III: Slight-increase period; Total Phase: Filling d

TABLE 2 Correlations of hormonal content in superior and inferior grains with mean grain filling rate at 86 and 102 days

Superior

Inferior

, ** Indicate correlation significance at the 0.05 and 0.01 probability levels, respectively $(\mathrm{n}=12)$ 